\title{
Sistem Informasi Pelayanan Pasien Berbasis Website Pada Puskesmas II Baturraden
}

\author{
Joko Dwi Mulyanto' ${ }^{1}$,Fatimahtuz Zahra ${ }^{2)}$ \\ 1) STMIK Nusa Mandiri Jakarta \\ 2) Universitas Bina Sarana Informatika \\ 1)joko.jdm@nusamandiri.ac.id , 2) zahrafatimahtuz7@gmail.com
}

\begin{abstract}
Puskesmas II Baturraden moves as one of the health agencies in the Baturraden area that has many patients who are treated every day. It cannot be denied, that patient care at this Puskesmas must be improved, starting from the service when the patient is going to register, then the examination is carried out until prescribing and taking drugs that must be used by the patient. The problem that is found in Baturraden II Health Center is in the patient's health service system, which is where the data needed when patient care takes place is still recorded and stored manually which results in frequent errors in recording patient data. Patient data that is stored is still in the form of archives, so that data accumulation and security from the data is not guaranteed. The usefulness of this research is to help process health services for patients who need data in each process, so as to provide faster and more effective and efficient services. With the existence of this Patient Service Information System, it is expected to help and facilitate the user in serving the patients who will seek treatment as in the search process of patient data more quickly and accurately, so that it can support the development of Patient Service Information System at Baturraden II Health Center.
\end{abstract}

Keywords: Information Systems, Patient Services, Puskesmas

\begin{abstract}
Abstrak: Puskesmas II Baturraden bergerak sebagai salah satu instansi kesehatan di daerah Baturraden ini memiliki banyak pasien yang berobat setiap harinya. Tidak dapat dipungkiri, bahwa pelayanan pasien pada Puskesmas ini pun harus di tingkatkan, mulai dari pelayanan pada saat pasien akan melakukan pendaftaran, kemudian selanjutnya dilakukan pemeriksaan sampai memberikan resep serta mengambil obat yang harus digunakan oleh pasien. Masalah yang terdapat di Puskesmas II Baturraden ini adalah pada sistem pelayanan kesehatan pasiennya, yaitu dimana data-data yang dibutuhkan saat pelayanan pasien berlangsung masih dicatat dan disimpan secara manual yang mengakibatkan sering terjadi kesalahan dalam pencatatan data pasien. Data pasien yang disimpan masih berupa arsip, sehingga terjadi penumpukan data dan keamanan dari datanya kurang terjamin. Kegunaan dalam penelitian ini adalah untuk membantu proses pelayanan kesehatan terhadap pasien yang membutuhkan data-data di setiap prosesnya, sehingga memberikan pelayanan yang lebih cepat dan efektif serta efisien. Dengan adanya Sistem Informasi Pelayanan Pasien ini diharapkan dapat membantu dan mempermudah user dalam melayanai para pasien yang akan berobat seperti pada proses pencarian data-data pasien menjadi lebih cepat dan akurat, sehingga dapat mendukung perkembangan Sistem Informasi Pelayanan Pasien pada Puskesmas II Baturraden ini.
\end{abstract}

Kata Kunci : Sistem Informasi, Pelayanan Pasien, Puskesmas unrestricted use, distribution, and reproduction in any medium, provided the original work is properly cited. (C2019 by author and I.JSE-Indonesian Journal on Software Engineering.

\section{A. PENDAHULUAN}

Kualitas pelayanan (Setyaningsih, 2013) Kualitas pelayanan didefinisikan sebagai perbedaan antara harapan pelanggan dengan kenyataan yang diterima. Pelayanan Puskesmas mengandalkan informasi secara intensif. Sehingga pemanfaatan kemajuan teknologi tidak 
menutup kemungkinan pekerjaan pengelolaan data dengan cara manual dapat digantikan dengan sistem informasi menggunakan komputer. Puskesmas II Baturraden adalah suatu organisasi kesehatan fungsional yang merupakan pusat pengembangan kesehatan masyarakat yang juga membina peran serta masyarakat disamping memberikan pelayanan secara menyeluruh dan terpadu kepada masyarakat diwilayah kerjanya dalam bentuk kegiatan pokok. Dengan pelayanan yang berkualitas serta terdapat dokter-dokter spesialis yang handal, telah mampu menangani berbagai macam keluhan pasien rawat jalan. Pasien harus melakukan pendaftaran untuk mendapatkan nomor urut pemeriksaan di poliklinik tertentu baik secara langsung datang ke rumah sakit atau melalui telepon.

Pengelolaan data secara manual seperti itu, mempunyai banyak kelemahan, selain membutuhkan waktu yang lama, keakuratannya juga kurang dapat diterima, karena kemungkinan kesalahan sangat besar. Permasalahan yang sering terjadi seperti laporan kunjungan pasien harian kurang akurat, kesalahan nomor urut pemeriksaan, kesulitan pencarian data pasien lama dan pembuatan data pasien baru yang tidak efisien. Masalah tersebut akan berpengaruh pada cepatnya layanan medis yang diinginkan oleh pasien rumah sakit.

Pasien pun tidak dapat cek terlebih dahulu nomor urut pendaftaran sudah sampai nomor keberapa serta kurangnya informasi jadwal dokter jaga. Kepuasan Pasien menurut (Azwar, 1994) Kepuasan pasien merupakan cerminan kualitas pelayanan kesehatan yang mereka terima. Melihat situasi tersebut, sudah sangatlah tepat jika rumah sakit menggunakan sisi kemajuan teknologi. Dengan adanya pendaftaran online, Dokter dapat mengetahui data pasien serta riwayat pasien dengan tepat dan dapat melihat jumlah antrian setiap pemeriksaan. pasien dapat melihat nomor urut sebelum melakukan pendaftaran. Pasien juga dapat melakukan pendaftaran di website tersebut sesuai dengan poliklinik dan dokter yang dituju dan mudah melihat jadwal dokter jaga, pasien dapat mengetahui diagnose bahkan riwayat penyakitnya didalam website. Pihak puskesmasdapat meminimalisir antrian diloket pendaftaran, mudah dalam melihat laporan kunjungan pasien secara akurat dan kepuasan pasien akan sangat menguntungkan pihak puskesmas dengan harapan agar pasien dapat melakukan kunjungan ulang ke puskesmas ketika sakit.

\section{B. TINJAUAN PUSTAKA}

\section{Sistem}

Sistem (Dini Indriani, 2019) "informasi adalah data yang sudah diklasifikasikan atau diolah diinterpretasikan untuk digunakan dalam proses pengambilan keputusan".sistem adalah seperangkat elemen yang membentuk kegiatan atau suatu prosedur atau bagian pengolahan yang mencari suatu tujuan-tujuan bersama dengan mengoperasikan data atau barang pada waktu tertentu untuk menghasilkan informasi atau energi atau barang.

Berikut menurut (J.Hutahean, 2014), menjelaskan tentang karakteristik dari sistemadalah:

a. Komponen Sistem (Components)

Suatu sitem terdiri dari sejumlah komponen yang saling berinteraksi dan bekerja sama untuk membentuk satu kesatuan. Komponen sistem dapat berupa sub sistem atau bagianbagian dari sistem.

b. Batasan sistem (boundary)

Daerah yang membatasi antara suatu sistem dengan sistem lainnya atau dengan lingkungan luar dinamakan dengan batasan sistem. Batasan sistem ini memungkinkan sistem dipandang sebagai satu kesatuan dan juga menunjukkan ruang lingkup (scope) dari sistem tersebut.

c. Lingkungan luar sistem (environment)

Apapun yang berada di luar batas dari sistem dan mempengaruhi sistem tersebut dinamakan dengan lingkungan luar sistem. Lingkungan luar yang bersifat menguntungkan 
wajib dipelihara dan yang merugikan harus dikendalikan agar tidak mengganggu kelangsungan sistem.

d. Penghubung sistem (interface)

Media penghubung diperlukan untuk mengalirkan sumber-sumber daya dari sub sistem ke sub sistem lainnya dinamakan dengan penghubung sistem.

e. Masukkan sistem (input)

Energi yang dimasukkan ke dalam sistem dinamakan dengan masukan sistem (input) dapat berupa perawatan dan masukan sinyal. Perawatan ini berfungsi agar sistem dapat beroperasi dan masukan sinyal adalah energi yang diproses untuk menghasilkan keluaran (output).

f. Keluaran Sistem (Output)

Pengolah sistem Untuk mengolah masukan menjadi keluaran diperlukan suatu pengolah yang dinamakan dengan pengolah sistem.

g. Sasaran sistem (Objective)

Sistem pasti memiliki tujuan atau sasaran yang sangat menentukan input yang dibutuhkan oleh sistem dan keluaran yang dihasilkan.

h. Pengolah Sistem (Process)

Suatu sistem dapat mempunyai suatu proses yang akan mengubah masukan menjadi keluaran.

\section{Informasi}

Informasi (A.Herliana, 2016) Informasi adalah "kumpulan data yangrelevan danmempunyai arti yang menggambarkan suatu kejadian-kejadian atau kegiatan-kegiatan. "Informasi (E. Mulyanah, 2016), " informasi adalah data yang sudah diolah menjadi sebuah bentuk yang berarti bagi pengguna, bermanfaat dalam pengambilan keputusan saat ini atau mendukung sumber informasi".

Informasi adalah sekumpulan data atau fakta yang telah diproses dan diolah sedemikian rupa sehingga bermanfaat bagi orang lain untuk menggambarkan suatu kondsi atau keadaan tertentu.

Data adalah fakta-fakta mentah kemudian dikelola sehingga menghasilkan informasi yang penting bagi sebuah perusahaaan atau organisasi.

\section{Sistem Informasi}

Sistem informasi menurut (Dini Indriani, 2019) "Sistem Informasi adalah kumpulan dari perangkat keras dan peragkat lunak komputer serta perangkat manusia yang akan mengolah data menggunakan perangkat keras dan perangkat lunak tersebut.

Sistem informasi dapat didefinisikan sebagai kumpulan elemen yang saling berhubungan satu sama lain yang membentuk satu kesatuan unuk mengintegrasikan data, memproses dan menyimpan serta mendistribusikan informasi. Dengan kata lain, Sistem informasi merupakan kesatuan elemen-elemen yang saling berinteraksi secara sistematis dan teratur untuk menciptakan dan membentuk aliran informasi yang akan mendukung pembuatan keputusan dan melakukan kontrol terhadap jalannya perusahaan.

\section{Internet}

Internet (Tasiati, 2017), bahwa "Internet sebetulnya singkatan dari kata Interconnected Networking. Networking artinya jaringan, sedang Interconnected berarti saling berkaitan/terkoneksi. Sehingga internet adalah jaringan komputer yang saling terkoneksi".

Dalam mengatur integritas dan komunikasi jaringan internet menggunakan sebuah protocol yang biasa disebut TCP/IP. TCP singkatan dari Transfer Control Protocol sementara IP 
singkatan dari Internet Protocol.. Kegunaan dari TCP yaitu untuk memastikan bahwa semua koneksi bekerja sebagaimana mestinya, sementara IP berfungsi melakukan transfer data dari sebuah komputer ke komputer lainnya. Sehingga TCP/IP secara umum berfungsi memilih rute terbaik untuk transmisi data, atau memilih rute alternatifnya jika suatu rute tidak fisibel untuk transmisi data.

\section{a. Website}

Website (Tasiati, 2017) "Website adalah sebutan bagi sekelompok halaman web (web page), dan umumnya merupakan bagian dari suatu nama domain (domain name) atau sub domain dalam World Wide Web (WWW) di internet".

Secara termologi pengertian website adalah kumpulan dari halaman-halaman situs atau link yang biasanya terangkum dalam sebuah sebuah domian atau subdomain yang tepatnya berada dalam World wide web (WWW) di Internet. Sebuah halaman web adalah dokumen yang ditulis dalam format hypertextMarkup Language (HTML), yang hampir selalu bias diakses melalui HTTP, yaitu protocol yang menyampaikan informasi dari server website untuk ditampilkan kepada para pmakai melalui web browser. Halaman-halaman dari sebuah wesite yang diidentifikasi oleh Uniform Resource Locator (URL) biasa disebut homepage atau domain name.

\section{b. Web Browser}

Web Browser (Y. Kristania, 2017), bahwa "Web Browser adalah aplikasi perangkat lunak yang memungkinkan penggunanya untuk berinteraksi dengan teks, image, video, games dan informasi lainnya yang berlokasi pada halaman web pada World Wide Web (WWW) atau Local Area Network (LAN)".

\section{c. Web Server}

Web Server (Y. Kristania, 2017), bahwa "Web Server merupakan perangkat lunak pada server yang memiliki fungsi sebagai penerima permintaan (request) yang berupa halaman web dari client dan mengirim kembali (respons) hasil yang diminta dalam bentuk halaman-halaman web".

Web server (A. Handayani, 2018), Web Server adalah program aplikasi yang memiliki fungsi sebagai tempat menyimpan dokumen-dokumen web.

Kita dapat mengubah isi dari website yang kita buat, kita membutuhkan program PHP. Script-script PHP tersebut yang berfungsi membuat halaman website menjadi dinamis. Contoh web server yang dipakai adalah Apache.

\section{d. Bahasa Pemrograman}

Beberapa bahasa pemrograman yang digunakan oleh penulis untuk membuat sebuah website diantaranya yaitu PHP, HTML, JavaScript dan lain sebagainya.

\section{1) Hypertext Markup Language (HTML)}

HTML (Y. Kristania, 2017) "HTML adalah menjelaskan tentang HTML singkatan dari Hyper Text Markup Language, yaitu skrip yang berupa tag-tag untuk membuat dan mengatur struktur website".

HTML (E. Mulyanah, 2016) "Hypertext Markup Language atau HTML dalam ilmu komputer merupakan bahasa pemformatan teks untuk dokumen-dokumen pada jaringan komputer yang dikenal sebagai World Wide Web (WWW)".

\section{2) JavaScript}

JavaScript ( E. Mulyanah, 2016) "Javascript merupakan skrip yang paling banyak digunakan dalam pemrograman web pada sisi client dewasa ini. Dengan adanya Javascript sebuah web akan menjadi lebih hidup, cepat, dan tampil lebih menawan dengan sebuah animasi ". 
Dengan adanya bahasa ini, kemampuan dokumen HTML menjadi semakin luas. Dengan menggunakan JavaScript dimungkinkan untuk mengimplementasikan tugas yang bersifat interaktif tanpa berhubungan dengan server.

Beberapa contoh yang bisa dilakukan melalui JavaScript:

a. Menampilkan jam lokal pada halaman web.

b. Mengatur warna latar belakang halaman web.

c. Mengganti gambar ketika pemakai menempatkan petunjuk mouse ke suatu gambar.

d. Memvalidasi keabsahan data yang dimasukan oleh pemakai.

e. Menandai semua data yang akan dihapus dengan cara memberi tanda centang pada kotak kecil. Hal seperti ini biasa disediakan pada pembaca e-mail yang berbasis web.

\section{3) Personal Hypertext Preprocessor (PHP)}

PHP (C. Kesuma, 2019), "PHP Hypertext preprocessor", merupakan bahasa scripting tingkat tinggi yang dipasang pada dokumen HTML".

PHP ( E. Mulyanah, 2016), bahwa "PHP merupakan bahasa yang hanya dapat berjalan pada server yang hasilnya dapat ditampilkan pada client".

Jadi, PHP (Hypertext Preprocessor) merupakan bahasa pemrograman yang digunakan untuk membuat situs web dan bisa digunakan bersamaan dengan HTML.

\section{4) JQuery}

JQuery (Tasiati, 2017), jQuery adalah javascript library, atau kumpulan kode atau fungsi javascript siap pakai, sehingga mempermudah dan mempercepat kita dalam membuat kode javascript.

\section{5) Cassading Style Sheet (CSS)}

CSS (A. Handayani, 2018), "CSS menjelaskan tentang bahwa CSS singkatan dari Cascading Style Sheets, yaitu skrip yang digunakan untuk mengatur desain website". CSS ( Tasiati, 2017), "CSS adalah singkatan dari Cascading Style Sheets. CSS adalah bahasa pengkodean yang digunakan untuk menata gaya tampilan halaman web agar lebih cantik dan indah saat ditampilkan di web browser".

Ada dua jenis CSS yang dapat digunakan yaitu CSS yang bersifat internal dan eksternal. Akan lebih mudah menggunakan yang eksternal, karena script CSS akan tersimpan berupa file CSS tersendiri, jadi akan lebih mudah dalam melakukan pengeditan, karena biasanya dihubungkan dengan link. Jika ingin melakukan perubahan format cukup dengan melakukan perubahan pada file CSS, maka halaman yang terhubung dengan file CSS tersebut akan ikut berubah. Jika menggunakan CSS bersifat internal pada halaman, maka bila ada perubahan format harus melakukan banyak pengeditan pada semua file.

Kelebihan dari penggunaan CSS jika dibandingkan dengan hanya menggunakan kode HTML saja yaitu lebih hemat waktu dan lebih mudah dalam mengedit

halaman web. Hal ini dikarenakan CSS fungsinya seperti master halaman. Jadi ketika ingin mengubah seluruh web hanya cukup mengubah dari file CSS-nya tanpa perlu satu per satu dari tiap halaman. Karena sekali ditulis, maka CSS akan berlaku untuk semua halaman web. Sedangkan kekurangannya adalah beberapa kode CSS yang berjalan baik pada satu web browser, belum tentu bisa aktif pada web browser yang lain. 


\section{6) Adobe Dreamweaver CS6}

Adobe dreamweaver (C. Kesuma, 2019) "Adobe Dreamweaver CS6 Merupakan salah satu aplikasi populer yang digunakan untuk mendesain sekaligus melakukan pemrograman web".

Program ini banyak digunakan oleh pengembang web karena fitur-fiturnya yang menaarik dan kemudahan penggunaannya".

\section{METODE PENELITIAN}

\section{Metode Pengembangan Perangkat Lunak}

Metode yang digunakan pada pengembangan perangkat lunak ini menggunakan

metode waterfall Menurut (Rossa A. Salahudin, 2014) menjelaskan tentang metode pengembangan sistem yaitu waterfall. Metode air terjun (waterfall) sering juga disebut model sekuensial linier (sequential linear) atau alur hidup klasik (classic life cycle). Model air terjun menyediakan pendekatan alur hidup terurut mulai dari analisis, desain, pengodean, pengujian, dan pemeliharaan.

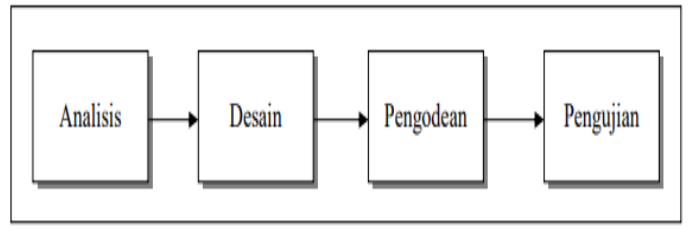

Gambar 2. Ilustrasi Model Waterfall

\section{Teknik pengumpulan Data}

Tenik pengumpulan data yang digunakan oleh penulis dalam melakukan pengumpulan data adalah :

a. Observasi

Penulis melakukan pengamatan-pengamatan langsung ke puskesmas II Baturraden terhadap kegiatan yang berhubungan dengan masalah yang belum terkomputerisasi. Hasil dari pengamatan tersebut langsungdicatat oleh penulis dan dari kegiatan observasi dapat diketahui kesalahan atau proses dan kegiatan tersebut.

b. Wawancara

Dalam penulisan laporan penelitian ini, untuk mendapatkan informasi secara lengkap maka penulis melakukan suatu metode ataupun suatu tanya jawab dengan Kepala Puskesmas II Baturraden mengenai semua kegiatan yang berhubungan dengan Sistem Pelayanan Pasien pada Puskesmas II Baturraden.

c. Studi Pustaka

Selain melakukan kegiatan diatas penulis juga melakukan sesuatu kepustakaan melalui literatur-literatur atau referensi-referensi yang ada diperpustakaan Universitas Bina Sarana Informatika maupun diperpustakaan lainnya.

\section{HASIL DAN PEMBAHAAN}

\section{Analisa Kebutuhan}

Analisa kebutuhan merupakan proses mengklasifkasi objek berdasarkan data yang diperoleh dari perusahaan. Proses ini digunakan untuk membangun website yang interaktif sesuai dengan kebutuhan user.

a. Analisa Kebutuhan Pengguna 
Internet telah membawa perubahan yang sangat besar dalam segala aspek kehidupan masyarakat. Salah satunya untuk dunia kesehatan yang dapat mempermudah input dan output sebuah pengolahan data. Sistem informasi pelayanan pasien berbasis web merupakan sebuah input data yang dapat dilakukan dimana saja tanpa perlu bertatap muka dan dapat meluas tanpa batas dalam penyampaiannya. Masyarakat cukup memanfaatkan internet untuk dapat mengakses website tersebut.

b. Analisa Kebutuhan Sistem

Website sistem informasi pendaftaran pasien rawat jalan memiliki kebutuhan sistem sebagai berikut:

1) Data

Data merupakan sebuah file yang digunakan untuk mempermudah dalam mengisi pembuatan website.

2) Hak Akses

Sistem informasi pendaftaran dibuat agar dapat diakses oleh beberapa tingkatan pengguna. Masing-masing pengguna akan memperoleh menu yang terbatas sesuai dengan hak aksesnya.

3) Keamanan

Sistem Informasi Pelayanan pasien pada Puskesmas II Baturaden memerlukan sistem keamanan agar terhindar dari pihak-pihak yang tidak bertanggungjawab, sistem keamanan yang dimaksud adalah Password admin dan pasien di enkripsi agar tidak diketahui oleh pihak lain.

\section{Rancangan Antar Muka}

a. Rancangan Halaman Login Admin

Rancangan halaman login admin dan halaman admin ini digunakan sebelum admin masuk kehalaman admin untuk mengelola website, yaitu dengan cara memasukan nama dan passwordadmin.

b. Rancangan Halaman Utama Admin

Halaman ini adalah halaman utama administratorwebsite. Pada halaman ini admin dapat mengelola semua data yang ada pada website

c. Halaman Pasien

Pada halaman ini pasien dapat mengelola data pasien dan dapat mendaftar pemeriksan. 
IJSE - Indonesian Journal on Software Engineering, Vol.5, No. 2, Desember 2019, 121-134 pISSN: 2461-0690 I elSSN: 2714-9935

\section{Rancangan Basis Data}

\section{Entity Relationship Diagram (ERD)}

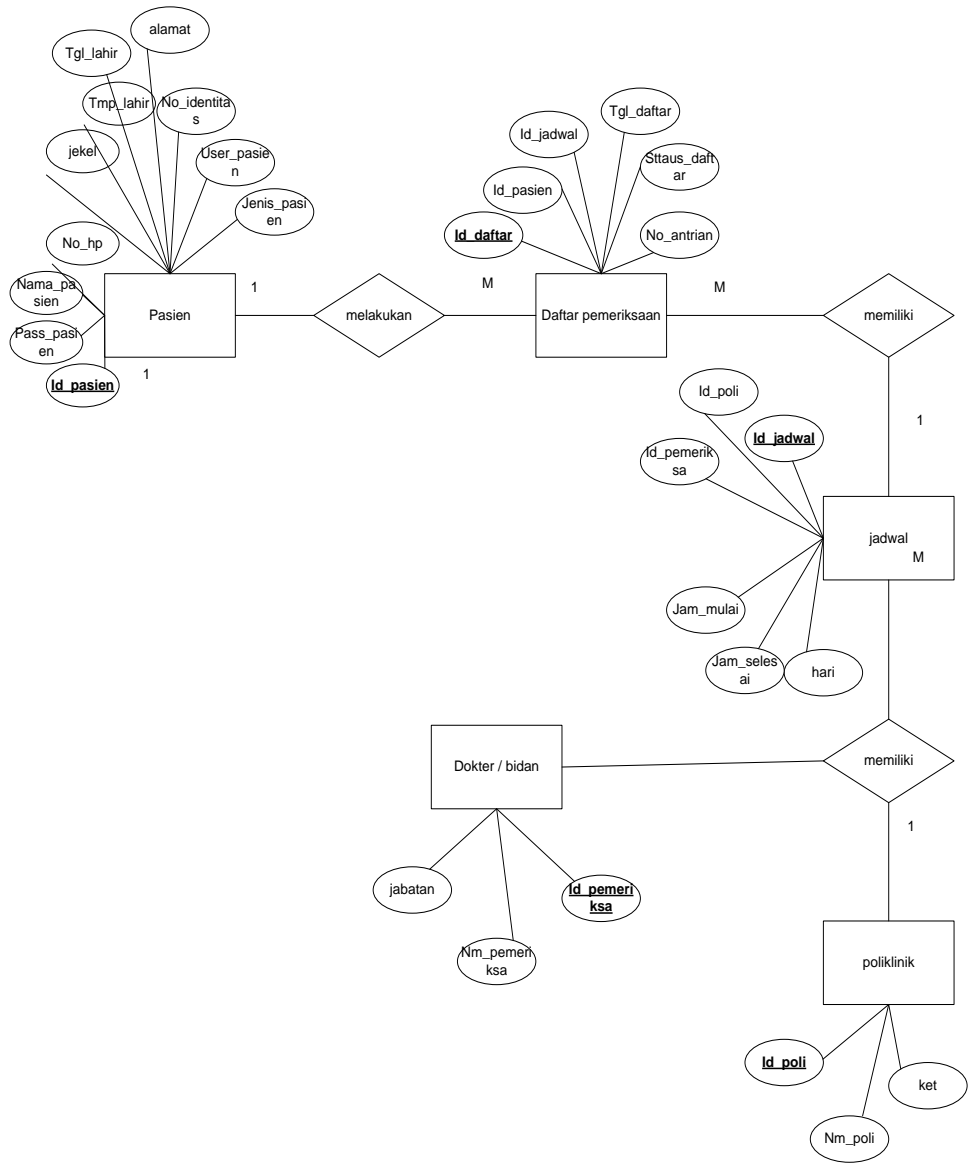

Gambar 2. Entity Relationship Diagram 
4. Rancangan Struktur Navigasi

a. Rancangan Struktur Navigasi Untuk Admin

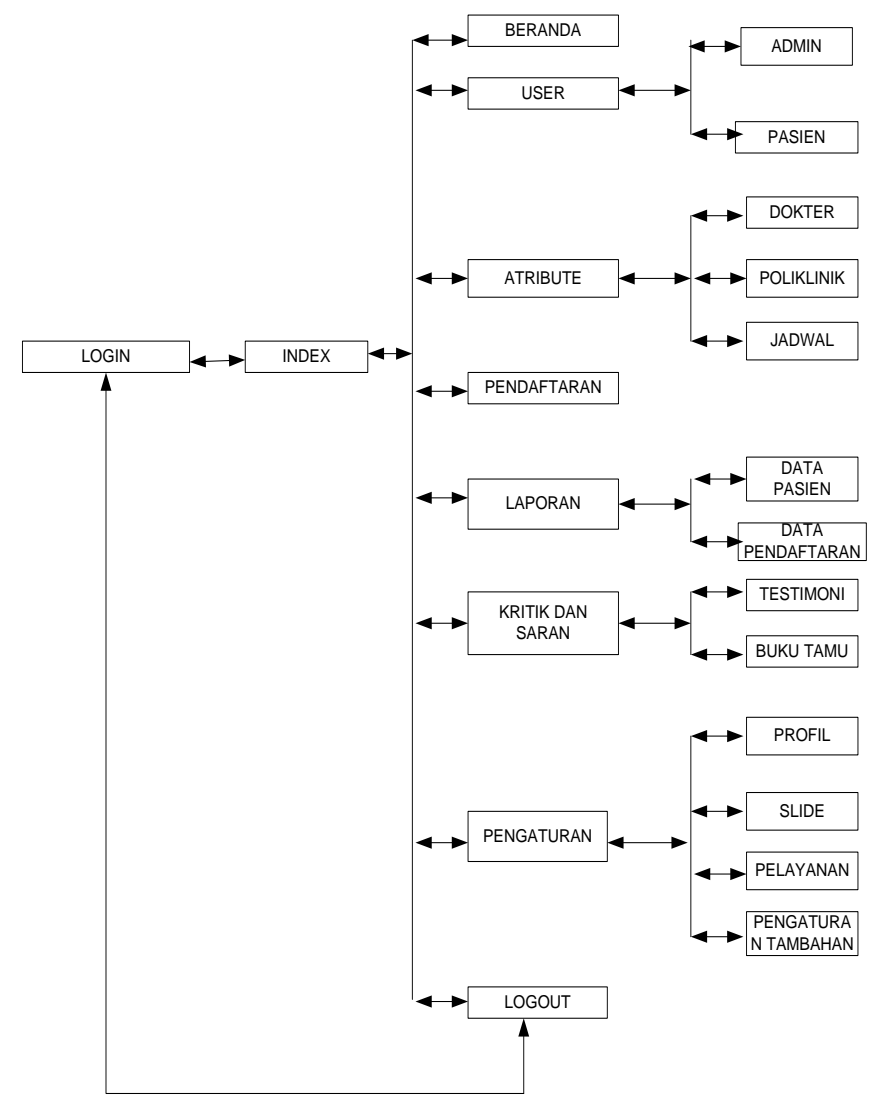

Gambar 3. Rancangan Struktur Navigasi Admin

b. Rancangan Struktur Navigasi Pengunjung

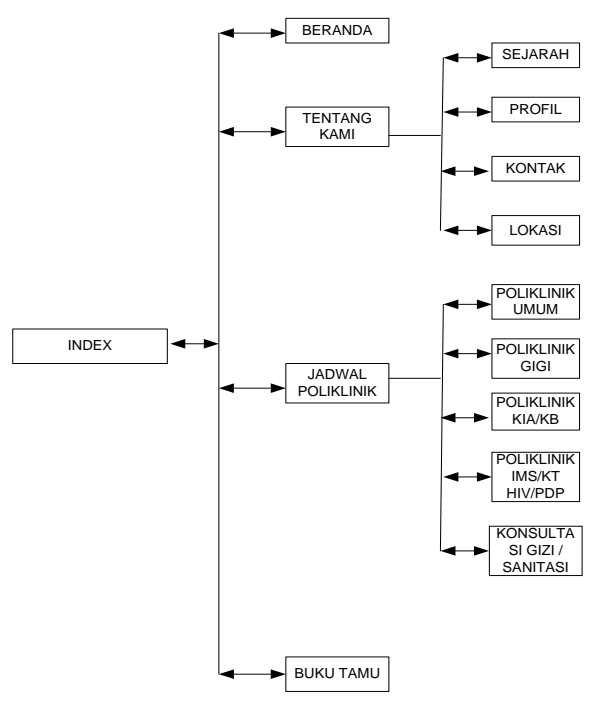


IJSE - Indonesian Journal on Software Engineering, Vol.5, No. 2, Desember 2019, 121-134 pISSN: 2461-0690 I elSSN: 2714-9935

Gambar 4. Rancangan Struktur Navigasi Pengunjung

c. Rancangan Struktur Navigasi Untuk Pasien

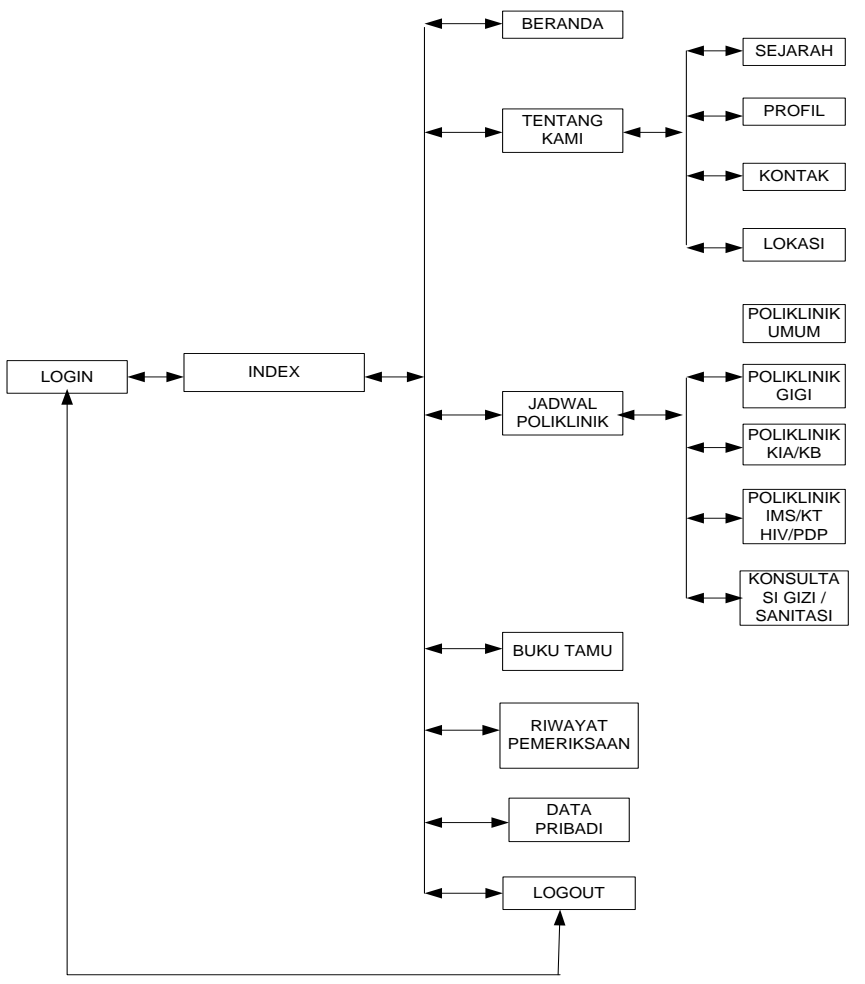

Gambar 5. Rancangan Struktur Navigasi Pasien

5. Pengujian Unit

a. Hasil pengujian Blackbox Testing Login Admin.

Tabel 1. Blackbox Testing Login Admin

\begin{tabular}{|c|c|c|c|c|c|}
\hline No. & $\begin{array}{c}\text { Sekenario } \\
\text { Pengujian }\end{array}$ & Test case & $\begin{array}{c}\text { Hasil Yang } \\
\text { Diarapkan }\end{array}$ & $\begin{array}{c}\text { Hasil } \\
\text { Pengujian }\end{array}$ & $\begin{array}{c}\text { Kesim } \\
\text { pulan }\end{array}$ \\
\hline 1. & $\begin{array}{c}\text { Nama admin dan } \\
\text { password tidak diisi } \\
\text { kemudian klik } \\
\text { tombol login }\end{array}$ & $\begin{array}{c}\text { Nama : (kosong) } \\
\text { Password: } \\
\text { (kosong) }\end{array}$ & $\begin{array}{c}\text { Sistem akan menolak } \\
\text { akses user dan } \\
\text { menampilkan } \\
\text { "Gagal login " }\end{array}$ & $\begin{array}{c}\text { Sesuai } \\
\text { harapan }\end{array}$ & Valid \\
\hline 2. & $\begin{array}{c}\text { Mengetikan Nama } \\
\text { Admin dan } \\
\text { password tidak diisi } \\
\text { kemudian klik } \\
\text { tombol login }\end{array}$ & $\begin{array}{c}\text { Nama : Admin } \\
\text { Password: } \\
\text { (kosong) }\end{array}$ & $\begin{array}{c}\text { Sistem akan menolak } \\
\text { akses user dan } \\
\text { menampilkan " Gagal } \\
\text { login " }\end{array}$ & $\begin{array}{c}\text { Sesuai } \\
\text { harapan }\end{array}$ & Valid \\
\hline 3. & $\begin{array}{c}\text { Nama admin tidak } \\
\text { diisi dan password } \\
\text { diisi kemudian klik } \\
\text { tombol login }\end{array}$ & $\begin{array}{c}\text { Nama: (kosong) } \\
\text { Password: admin }\end{array}$ & $\begin{array}{c}\text { Sistem akan menolak } \\
\text { akses user dan } \\
\text { menampilkan } \\
\text { " Gagal login " }\end{array}$ & $\begin{array}{c}\text { Sesuai } \\
\text { harapan }\end{array}$ & Valid \\
\hline
\end{tabular}




\begin{tabular}{|c|c|c|c|c|c|}
\hline 4. & $\begin{array}{c}\text { Mengetikan salah } \\
\text { satu kondisi salah } \\
\text { pada Nama Admin } \\
\text { atau password } \\
\text { kemudian klik } \\
\text { tombol login }\end{array}$ & $\begin{array}{c}\text { Nama : abcd } \\
\text { Password: } 1234\end{array}$ & $\begin{array}{c}\text { Sistem akan menolak } \\
\text { akses user dan } \\
\text { menampilkan } \\
\text { " Gagal login " }\end{array}$ & $\begin{array}{c}\text { Sesuai } \\
\text { harapan }\end{array}$ & Valid \\
\hline 5. & $\begin{array}{c}\text { Mengetikan Nama } \\
\text { Admin, password } \\
\text { dengan data yang } \\
\text { benar kemudian klik } \\
\text { tombol login }\end{array}$ & $\begin{array}{c}\text { Nama : admin } \\
\text { Password: admin }\end{array}$ & $\begin{array}{c}\text { Sistem akan } \\
\text { menerima akses login } \\
\text { dan kemudian } \\
\text { langsung } \\
\text { menampilkan menu } \\
\text { utama }\end{array}$ & $\begin{array}{c}\text { Sesuai } \\
\text { harapan }\end{array}$ & Valid \\
\hline
\end{tabular}

\section{b. Hasil Pengujian Black Box Testing Form Daftar Pasien}

Tabel 2. Black Box Testing Form Daftar Pasien

\begin{tabular}{|c|c|c|c|c|c|}
\hline No & Sekenario Pengujian & Test case & $\begin{array}{c}\text { Hasil Yang } \\
\text { Diarapkan }\end{array}$ & $\begin{array}{c}\text { Hasil } \\
\text { Pengujian }\end{array}$ & Kesimpulan \\
\hline 1 & $\begin{array}{l}\text { User tidak diisi atau diisi } \\
\text { dengan format salah } \\
\text { sedang yang lain diisi } \\
\text { dengan benar, lalu klik } \\
\text { "daftar" }\end{array}$ & $\begin{array}{l}\text { User: (kosong) } \\
\text { Password: } 123 \\
\text { Jenis : Anak } \\
\text { nama pasien : } \\
\text { ana } \\
\text { no hp : } \\
\text { 095677007699 } \\
\text { jenis Kelamin : } \\
\text { Perempuan } \\
\text { tempat lahir : } \\
\text { banyumas } \\
\text { tanggal lahir: } \\
\text { 1998-05-25 } \\
\text { alamat : } \\
\text { banyumas }\end{array}$ & $\begin{array}{l}\text { Sistem akan } \\
\text { menolak akses } \\
\text { user dan } \\
\text { menampilkan } \\
\text { " Harus Diisi “ } \\
\text { atau " format } \\
\text { email belum } \\
\text { benar " pada } \\
\text { form yang tidak } \\
\text { diisi. }\end{array}$ & $\begin{array}{c}\text { Sesuai } \\
\text { harapan }\end{array}$ & Valid \\
\hline 2 & $\begin{array}{l}\text { Password tidak diisi } \\
\text { sedang yang lain diisi } \\
\text { dengan benar, lalu klik } \\
\text { "daftar" }\end{array}$ & $\begin{array}{l}\text { User: via } \\
\text { Password: } \\
\text { (kosong) } \\
\text { Jenis : Anak } \\
\text { nama pasien : } \\
\text { ana } \\
\text { no hp : } \\
\text { 095677007699 } \\
\text { jenis Kelamin : } \\
\text { Perempuan } \\
\text { tempat lahir : } \\
\text { banyumas } \\
\text { tanggal lahir : } \\
\text { 1998-05-25 } \\
\text { alamat: } \\
\text { Banyumas }\end{array}$ & $\begin{array}{l}\text { Sistem akan } \\
\text { menolak akses } \\
\text { user dan } \\
\text { menampilkan } \\
\text { " Harus Diisi “ } \\
\text { pada form yang } \\
\text { tidak diisi. }\end{array}$ & $\begin{array}{c}\text { Sesuai } \\
\text { harapan }\end{array}$ & Valid \\
\hline 3 & $\begin{array}{l}\text { Jenis tidak diisi sedang } \\
\text { yang lain diisi dengan } \\
\text { benar, lalu klik "daftar" }\end{array}$ & $\begin{array}{l}\text { User : via } \\
\text { Password: } 123 \\
\text { Jenis : (kosong) } \\
\text { nama pasien : } \\
\text { nana } \\
\text { no hp: }\end{array}$ & $\begin{array}{l}\text { Sistem akan } \\
\text { menolak akses } \\
\text { user dan } \\
\text { menampilkan } \\
\text { "Harus Diisi " } \\
\text { pada form yang }\end{array}$ & $\begin{array}{c}\text { Sesuai } \\
\text { harapan }\end{array}$ & Valid \\
\hline
\end{tabular}


IJSE - Indonesian Journal on Software Engineering, Vol.5, No. 2, Desember 2019, 121-134 pISSN: 2461-0690 I elSSN: 2714-9935

\begin{tabular}{|c|c|c|c|c|c|}
\hline & & $\begin{array}{l}095677007699 \\
\text { jenis Kelamin : } \\
\text { Perempuan } \\
\text { tempat lahir: } \\
\text { banyumas } \\
\text { tanggal lahir: } \\
\text { 1998-05-25 } \\
\text { alamat: } \\
\text { banyumas }\end{array}$ & tidak diisi. & & \\
\hline 4 & $\begin{array}{l}\text { Nama tidak diisi sedang } \\
\text { yang lain diisi dengan } \\
\text { benar, lalu klik "daftar" }\end{array}$ & $\begin{array}{l}\text { User : via } \\
\text { Password: } 123 \\
\text { Jenis : Anak } \\
\text { nama pasien : } \\
\text { (kosong) } \\
\text { no hp : } \\
095677007699 \\
\text { jenis Kelamin: } \\
\text { Perempuan } \\
\text { tempat lahir : } \\
\text { banyumas } \\
\text { tanggal lahir : } \\
\text { 1998-05-25 } \\
\text { alamat: } \\
\text { banyumas }\end{array}$ & $\begin{array}{l}\text { Sistem akan } \\
\text { menolak akses } \\
\text { user dan } \\
\text { menampilkan } \\
\text { "Harus Diisi " } \\
\text { pada form yang } \\
\text { tidak diisi. }\end{array}$ & $\begin{array}{c}\text { Sesuai } \\
\text { harapan }\end{array}$ & Valid \\
\hline 5 & $\begin{array}{l}\text { No hp tidak diisi sedang } \\
\text { yang lain diisi dengan } \\
\text { benar, lalu klik "daftar" }\end{array}$ & $\begin{array}{l}\text { User : via } \\
\text { Password: } 123 \\
\text { Jenis : Anak } \\
\text { nama pasien : } \\
\text { nana } \\
\text { no hp : (kosong) } \\
\text { jenis Kelamin: } \\
\text { Perempuan } \\
\text { tempat lahir: } \\
\text { banyumas } \\
\text { tanggal lahir: } \\
\text { 1998-05-25 } \\
\text { alamat: } \\
\text { banyumas }\end{array}$ & $\begin{array}{l}\text { Sistem akan } \\
\text { menolak akses } \\
\text { user dan } \\
\text { menampilkan } \\
\text { " Harus Diisi “ } \\
\text { pada form yang } \\
\text { tidak diisi. }\end{array}$ & $\begin{array}{c}\text { Sesuai } \\
\text { harapan }\end{array}$ & Valid \\
\hline 6 & $\begin{array}{l}\text { Jenis kelamin tidak diisi } \\
\text { sedang yang lain diisi } \\
\text { dengan benar, lalu klik } \\
\text { "daftar" }\end{array}$ & $\begin{array}{l}\text { User : via } \\
\text { Password: } 123 \\
\text { Jenis : Anak } \\
\text { nama pasien : } \\
\text { nana } \\
\text { no hp : } \\
095677007699 \\
\text { jenis Kelamin : } \\
\text { (kosong) } \\
\text { tempat lahir : } \\
\text { banyumas } \\
\text { tanggal lahir: } \\
\text { 1998-05-25 } \\
\text { alamat: } \\
\text { banyumas }\end{array}$ & $\begin{array}{l}\text { Sistem akan } \\
\text { menolak akses } \\
\text { user dan } \\
\text { menampilkan } \\
\text { "Harus Diisi “ } \\
\text { pada form yang } \\
\text { tidak diisi. }\end{array}$ & $\begin{array}{c}\text { Sesuai } \\
\text { harapan }\end{array}$ & Valid \\
\hline 7 & $\begin{array}{l}\text { Tempat lahir tidak diisi } \\
\text { sedang yang lain diisi } \\
\text { dengan benar, lalu klik } \\
\text { "daftar" }\end{array}$ & $\begin{array}{l}\text { User: via } \\
\text { Password: } 123 \\
\text { Jenis : Anak } \\
\text { nama pasien : } \\
\text { nana } \\
\text { no hp: }\end{array}$ & $\begin{array}{l}\text { Sistem akan } \\
\text { menolak akses } \\
\text { user dan } \\
\text { menampilkan } \\
\text { "Harus Diisi “ } \\
\text { pada form yang }\end{array}$ & $\begin{array}{c}\text { Sesuai } \\
\text { harapan }\end{array}$ & Valid \\
\hline
\end{tabular}




\begin{tabular}{|c|c|c|c|c|c|}
\hline & & $\begin{array}{l}095677007699 \\
\text { jenis Kelamin : } \\
\text { perempuan } \\
\text { tempat lahir: } \\
\text { (kosong) } \\
\text { tanggal lahir: } \\
\text { 1998-05-25 } \\
\text { alamat: } \\
\text { banyumas }\end{array}$ & tidak diisi. & & \\
\hline 8 & $\begin{array}{l}\text { Tanggal lahir tidak diisi } \\
\text { sedang yang lain diisi } \\
\text { dengan benar, lalu klik } \\
\text { "daftar" }\end{array}$ & $\begin{array}{l}\text { User: via } \\
\text { Password: } 123 \\
\text { Jenis : Anak } \\
\text { nama pasien : } \\
\text { nana } \\
\text { no hp : } \\
095677007699 \\
\text { jenis Kelamin: } \\
\text { perempuan } \\
\text { tempat lahir: } \\
\text { Banyumas } \\
\text { tanggal lahir: } \\
\text { (kosong) } \\
\text { alamat: } \\
\text { banyumas }\end{array}$ & $\begin{array}{l}\text { Sistem akan } \\
\text { menolak akses } \\
\text { user dan } \\
\text { menampilkan } \\
\text { "Harus Diisi “ } \\
\text { pada form yang } \\
\text { tidak diisi. }\end{array}$ & $\begin{array}{c}\text { Sesuai } \\
\text { harapan }\end{array}$ & Valid \\
\hline 9 & $\begin{array}{l}\text { Alamat tidak diisi } \\
\text { sedang yang lain diisi } \\
\text { dengan benar, lalu klik } \\
\text { "daftar" }\end{array}$ & $\begin{array}{l}\text { User: via } \\
\text { Password: } 123 \\
\text { Jenis : Anak } \\
\text { nama pasien : } \\
\text { nana } \\
\text { no hp : } \\
\text { 095677007699 } \\
\text { jenis Kelamin : } \\
\text { perempuan } \\
\text { tempat lahir: } \\
\text { Banyumas } \\
\text { tanggal lahir : } \\
\text { 1998-05-25 } \\
\text { alamat: } \\
\text { (kosong) }\end{array}$ & $\begin{array}{l}\text { Sistem akan } \\
\text { menolak akses } \\
\text { user dan } \\
\text { menampilkan } \\
\text { "Harus Diisi “ } \\
\text { pada form yang } \\
\text { tidak diisi. }\end{array}$ & $\begin{array}{c}\text { Sesuai } \\
\text { harapan }\end{array}$ & Valid \\
\hline
\end{tabular}

\section{E. KESIMPULAN}

Berdasarkan pembahasan pada bab sebelumnya, mengenai pembuatan sistem informasi pelayanan pasien berbasis web pada Puskemas II Baturraden dapat diambil beberapa kesimpulan. Diantaranya adalah :

a. Dapat mempermudah penyampaian informasi pendaftaran pasien ke masyarakat tanpa batasan waktu.

b. Memudahkan pasien untuk mengetahui jadwal dokter sesuai dengan yang diinginkan.

c. Mempersingkat waktu pendaftaran online ini karena dapat dilakukan tanpa harus datang ke Puskesmas.

d. Dari segi perusahaan dapat mempermudah pengarsipan data pasien rawat jalan mengenai riwayat pendaftaran pasien.

e. Memudahkan pegawai bagian pendaftaran puskesmas untuk mengatur nomor antrian pasien serta meminimalisir penginputan data pasien baru yang mendaftar. 
IJSE - Indonesian Journal on Software Engineering, Vol.5, No. 2, Desember 2019, 121-134 pISSN: 2461-0690 I elSSN: 2714-9935

\section{REFERENSI}

Azwar, A. (1994). Pengantar AdministrasiKesehatan, Edisi ketiga. Tanggerang: Binarupa Aksara.

Dini Indriani, A. I. W. (2019). Unified Modelling Language Menurut ( Prihandoyo , 2018: 127 ): Unifield Modeling Language merupakan salah satu metode pemodelan visual yang digunakan dalam perancangan dan pembuatan sebuah software berorientasikan pada. Sistem Informasi Hafalan Terbaik Dalam Munaqosah Tahfizhul Qur'an Menggunakan Metode Ahp, 7(1), 1-11.

Handayani vembria rose, Ragil Wijianto, A. A. (2018). Sistem Informasi Pendaftaran Seleksi Kerja Berbasis Web Pada Bkk (Bursa Kerja Khusus) Tunas Insan Karya Smk Negeri 2 Banyumas 1. Jurnal Evolusi, 6(1), 76-84.

Herliana, A., \& Rasyid, P. M. (2016). Sistem Informasi Monitoring Pengembangan Software pada Tahap Development Berbasis Web. Jurnal Informatika, 3(1), 41-50.

Hutahean, J. (2014). KONSEP SISTEM INFORMASI. In Climate Change 2013 - The Physical Science Basis. https://doi.org/10.1017/CBO9781107415324.004

Kesuma, C., \& Kholifah, D. N. (2019). Sistem Informasi Akademik Berbasis Web pada LKP Rejeki Cilacap. Evolusi, 7(1), 82-88.

Kristania, Y., Maryani, I., \& Asyifudin, I. (2017). Sistem Informasi Akademik Berbasis Web Pada Smk Negeri 2 Banyumas. Jurnal Evolusi, 5(2), 82-89.

Mulyanah, E., \& Hellyana, C. M. (2018). Sistem Informasi Pemesanan Minuman Berbasis Client Server Pada Kampung Dahar Purwokerto. Jurnal Evolusi, 6(2), 1-8.

Rosa A.S dan Shalahudin. (2014). Rekayasa Perangkat Lunak.

Setyaningsih, I. (2013). Analisis Kualitas Pelayanan Rumah Sakit Terhadap Pasien Menggunakan Pendekatan Lean Servperf (Lean Service Dan Service Performance). Spektrum Industri, 2(5), 133-143.

Tasiati, \& Corie Mei Hellyana. (2017). Sistem Informasi Penjualan Berbasis Web Pada Genom Bag Purwokerto. Evolusi, 5(2), 66-73. https://doi.org/10.1177/0963721415620776 